\title{
Pre-residency boot camps calm medical graduate jitters
}

- Cite as: CMAJ 2018 August 13;190:E967-8. doi: 10.1503/cmaj.109-5642

Posted on cmajnews.com on July 24, 2018.

t's no secret that the transition from medical school to residency can be difficult. "Nothing will prepare you," residents warn on medical trainee forums. "Not sure if anyone could have convinced me that I would learn so much while feeling like such an idiot," one resident wrote. "There are a lot of piddly things you don't completely know how to do, like prepping, draping, positioning. These will make you look and feel stupid," another explained.

A growing number of medical schools in the United States are offering pre-residency boot camps to prepare graduates and fill gaps in their training. The model is also starting to crop up in Canada, with boot camps for incoming family medicine and neurosurgery residents. Although these courses may boost trainees' confidence heading into residency, it's less clear what difference they make in the long run.

In theory, medical school should be preparation enough. But studies from around the world show residents feel unprepared, particularly when it comes to basic clinical skills like prescribing and emergency care. Residency program directors report that trainees struggle with communication, organization and professionalism. One study found that most first-year family medicine residents were able to perform only five of 15 procedures expected by program directors.

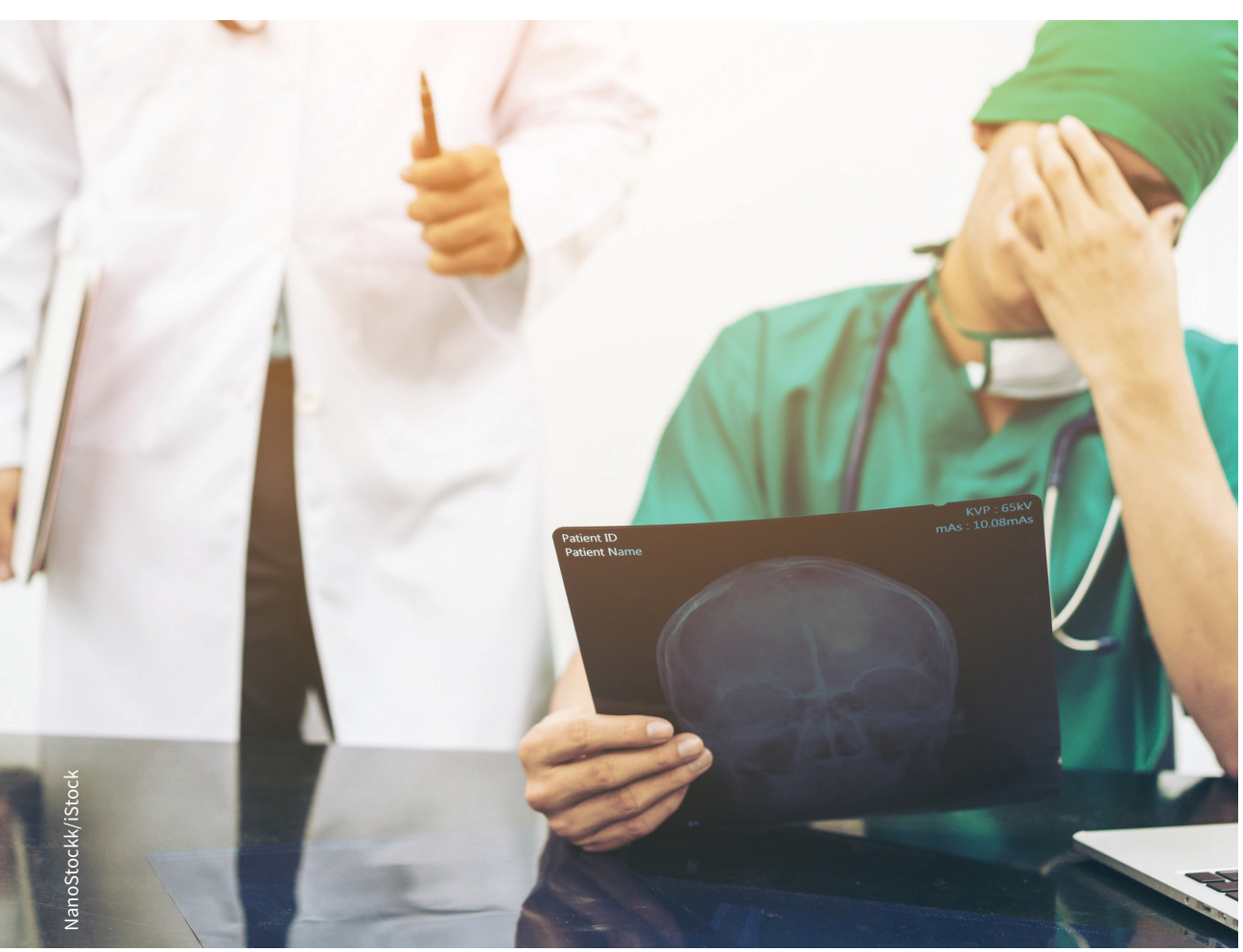

Medical graduates often feel unprepared for residency, so some schools offer boot camps to fill training gaps.
"There is a need to recalibrate what is expected of new residents," according to Dr. Christian Jones, assistant director of the surgical residency program at Johns Hopkins University School of Medicine. Medical students are expected to learn far more information now than even five years ago, he explained. "Unfortunately, there's so much to learn that some things tend to be overlooked."

Often, graduates end up lacking socalled soft skills, such as time management, effective teamwork and resiliency. Johns Hopkins was among 71 US schools that recently piloted a week-long boot camp for incoming surgical interns. In addition to providing training on a variety of clinical skills, the course includes panel discussions with residents and advanced practice providers on what they wish trainees knew from day one.

Many schools also offer general residency prep courses and boot camps for other specialties. These courses tend to focus on communication and life skills, as well as everyday tasks that might not have come up in medical school, such as how to do phone consults or creating admission orders. It is likely that more US residency programs will start to expect their residents to have taken part in such programs, according to Jones.

A meta-analysis of pre-residency boot camps showed they improve trainees' confidence and clinical skills before residency. However, there aren't objective data to show that translates into improved performance during residency. One study found that a pediatrics boot camp improved trainees' self-reported ability to perform certain clinical tasks, like infant lumbar puncture, but it didn't improve their soft skills in communication or increase their 
overall preparedness. Another study found that although a boot camp increased medical graduates' self-confidence before residency, the trainees were no different from other residents after six months.
This has led some trainees to question the value of these programs. On medical trainee forums, some people advise using the gap between medical school and residency to relax. "I suggest Xbox and legal adult beverages of your choice instead of boot camps," one resident writes. "Take naps. Sit in the sun."

Lauren Vogel, CMAJ 